\title{
Using Quality Cycle in Maintaining the Quality and Performance of Small-Scale Herbal Enterprises
}

\author{
Kartika Nuringsih $^{1 *}$, Rodhiah Rodhiah ${ }^{1}$, Khairina Natsir $^{1}$ \\ ${ }^{1}$ Faculty of Economics \& Business, Universitas Tarumanagara, Jakarta, 11470, Indonesia \\ "Corresponding author. Email: kartikan@fe.untar.ac.id
}

\begin{abstract}
This research explored the distinction in perception toward the activities of managing quality and achieving performance among small-scale herbal enterprises in the suburbs of Jakarta. Based on prior literatures, the model of quality is constructed by five dimensions, while the performance is elaborated by two dimensions. The study involved as many as 172 jamu peddlers from some places in Jakarta and its surroundings. The collecting of data was done through questionnaires and interviews. Respondents were divided into two different groups. The first group had not been introduced a quality model, whereas the other group had accepted the knowledge of managing quality. The quality cycle was used as an experimental approach for identifying the responses among respondents. Based on Mann-Whitney $U$ test, differences were found in four stages of managing the quality and competitive power. However, the study found the same responses in maintaining the service quality and surviving the bargaining power. This study proves the advantage of the quality cycle in introducing quality culture to the jamu community. Moreover, during the pandemic, understanding their perception within the concept of quality management is an important stage when designing the mechanism of quality cycle implementation in small-scale herbal enterprises.
\end{abstract}

Keywords: Herbal, performance, quality management, quality cycle, small-scale enterprises

\section{INTRODUCTION}

In some places in Central Java or Yogyakarta Province, there are some communities of women who have the skill and experience to make the traditional herbs. The capabilities are utilized in a commercial activity with producing the traditional herbs in the household scale. Familiarly, this community is called "jamu peddlers" which makes the use of local potentials as economically beneficial activities. Furthermore, the name "jamu" (pharmacopeia) is identical to herbs, whereas some generations have been consuming them for healing diseases or maintaining their health. Therefore, the keyword in this study places two terms that have the identical meaning, namely traditional herb, and jamu, of which both can be used interchangeably.

Basically, these activities have been recognized by the Ministry of Health through ministerial regulation Number 006 Year 2012 which is states as "An individual business utilizing traditional medicine ingredients in the form of fresh liquid to be marketed directly to customers" [1]. Aligned with the regulation, the task of this community is to combine various types of herbal medicine from traditional ingredients which are then used by its customers to maintain their health. Several kinds can be sold that consists of "Beras Kencur, Kunyit Asam, Cabe Puyang, Pahitan, Kunci Suruh, Kudu Laos, Uyup-Uyup, and Sinom" [2]. For this reason, they have a daily role as a seller of traditional herbs for people at some places in the suburbs of Jakarta and its surroundings.

Practically, the process to make the herb product is done auto-didactically, in a simple way, and unregistered in the
Ministry of Health. This condition is also depicted in the study of Torri (2013) [3], so that over time the role of these herb sellers will be increasingly marginalized in the future. [4]. The way to make this product is perceived as less hygienic so that modern people may be less interested to consume it. However, for long-run, this business has provided income to the family and local society. It shows the participation among women in sustaining tradition and taking a role in the distribution chain of the traditional medicine industry. For ensuring the safety and hygiene from the material preparation until the consumption, the sellers need information related to the quality.

Previously, the basis of quality as stated by Goetsch \& Davis [5], was defined as a dynamic state related to the five aspects such as products, services, people, processes, and environment that meet or exceed the customer expectations". Previously, Feigenbaum noted the assessment of quality depending on the actual experience among customers. Based on this reason, the community needs to be motivated about the knowledge of quality management.

For understanding the quality, people are introduced about the Total Quality Management (TQM), while the implementation of this model can be done by through Total Quality Cycle. At the corporate level, [6] highlighted TQM as the systematic quality-improvement approach to enhance the performance including "quality, productivity, customer satisfaction, and profitability". In line with Sadikoglu \& Olcay, [7] "described TQM as a firm-wide management philosophy which has the goals in continuously improving, specifically the quality of products, services, and processes, 
by focusing on the need of customers and enhancing the customers' satisfaction". Moreover, the same goals were noted by [8][9][10][11], so the current study adopted a quality system for designing simple guidance for herbal enterprises in urban areas.

Aligned to the model, the "quality cycle is used as a conceptual approach in building a quality culture which has the goals to increase the quality, productivity, and bargaining power of business". Prior researches [12][13][14][15][16] stated the quality cycle's benefits for managing employees and corporate performance. For this reason, preliminary studies were done to introduce some simple points of TQM to this community [2][17], so further study has the goal to create quality simulation with the sellers.

A previous study [18] developed the quality-circle stages such as problem identification, problem selection, problem analysis, alternative solution generation, the best solution selection, action plan preparation, management solution presentation, and solution implementation. The adaptation can be suitable for household businesses to improve their bargaining and competitive power. Both are dimensions for measuring the herbal enterprises' performance. In line with [19], knowledge management is an important aspect in TQM.

This study constructed two groups of sellers as experiments in understanding the quality approach. It is expected as the novelty of this study. The Group-1 consisted of some sellers who had not previously recognized the quality-management stages. On contrary, the members of Group-2 had understood about these stages from the material preparation till the establishment of social relationship. This mechanism is designed as a quality-cycle approach, then investigates the different responses in perceiving the quality management and performance.

Lastly, the government and related stakeholders can take advantage of this result in promoting quality awareness among herbal-medicine traders. Besides, it is necessary to remind the loyal customers to pay attention to the cleanliness and safety of herbal products. This aims to maintain the sustainability of local wisdom specifically in consuming traditional herbal medicine. Moreover, during Covid-19 pandemic, many consumers took advantage of herbal products to maintain their stamina. Therefore, the awareness of personal hygiene and the cleanliness of process from making until serving those herbal products must be a priority for herbal sellers.

\section{METHOD}

The population of this study involves the community of jamu peddlers in the suburbs of Jakarta and its surrounding. Samples were obtained as many as 172 respondents by using the Snowball Method. The processing of observed data was done on two big groups, whereas every group consisted of ten small-groups based on the location of respondents. Each big group consisted of 86 respondents whereas the first group had not been introduced to the quality model, while on the contrary, they had received the treatment about it. The benefit of quality cycle is as an experimental tool when introducing the quality.

The dimensions for measuring Quality Management (QM) was resulted from early studies by [2] and [17] with the description as follows: (1) "Quality management in input processing" (QMI) describes the input process represented by 10 items; (2) "Quality management in jamu making" (QMM) represents the making process with 10 items; (3) "Quality management in output processing" (QMO) describes the output process consisting of 5 items; (4) "Quality management in service processing" (QMS) represents the service process with totally 6 items; and (5) "Quality management in social relationship" (QMR) describes the societal relationship consisting of 7 items. Totally, there are 38 indicators in this study.

Performance is constructed by two dimensions. Based on some previous studies, the break-down indicators are as follows: Competitive Power (CP) is measured by profit, stability on sales, respect to quality, and focus on suppliers' quality, while Bargaining Power (BP) is measured by image, customer satisfaction, and social relationship $[20][21][22][23][24][25][26],[9]$. Based on these results, the item of performance consisted of 7 indicators.

The instruments were then developed into a questionnaire using the ordinal scale ranging from 1 to 5 with the meanings from "never done" until "always done" for the construct of quality management. The measurement of performance used the Likert scale of 1-5 with the meanings from "strongly disagree" to "strongly agree". Data was collected through questionnaires and interviews during June-July 2017. To ensure the accuracy of the conceptual measurement scale, we could use the score of Cronbach's Alpha. Garson [27] classified this value with the criteria as follows: 0.70 (acceptable), 0.80 (satisfying), and 0.90 (very satisfying). So, the cut-off value must be higher than 0.70. Meanwhile, the number of "corrected item-total correlations" must be higher than 0.20

Data analysis used the Mann-Whitney U-test and other tests including normality, reliability, validity, Kaiser-MeyerOlkin (KMO), and Bartlett's Tests". The result of the Kolmogorov-Smirnov Test shows the score lower than 5\%. It means that the data condition is not normal. Thus, the data analysis method used the non-parametric statistics of MannWhitney to analyze the different responses specifically on the case of a pair of independent-sample groups. The development of hypotheses was based on the previous studies conducted by [2][3][4] [17] and improved by [6][7][22][28]. The two groups were then analyzed for the differences in responses when perceiving the five dimensions in quality management and the two dimensions in performance. Totally, there are seven hypotheses tested in this research with the explanations as follows:

(1) $\mathbf{H}_{1 \mathrm{a}}$ : There is a distinction in ingredient preparation processing between the two groups of peddlers

(2) Ho: There is a difference in jamu making between the two groups of peddlers.

(3) $\mathbf{H}_{1 \mathbf{c}}$ : There is a distinction in output processing between the two groups of peddlers.

(4) $\mathbf{H}_{1 \mathrm{~d}}$ : There is a difference in customer servicing between the two groups of peddlers. 
(5) $\mathbf{H}_{1 \mathrm{e}}$ : There is a difference in building social relationship between the two groups of peddlers.

(6) $\mathbf{H}_{2 \mathrm{a}}$ : There is a disparity in perceiving the bargaining power between the two groups of peddlers.

(7) $\mathbf{H}_{2 \mathrm{~b}}$ : There is a disparity in understanding the competitive power between the two groups of peddlers.

\section{RESULTS AND DISCUSSIONS}

\subsection{The Profile of Respondents}

The profiling process in the first group is as follows: (1) the majority age was in the range of 40-50 years with a total of 36 respondents. There were even 5 women aged over 61 years and the youngest was $31-40$ years old (15 sellers). (2) Most duration in the range of 21-30 years belonged to 27 people, whereas 18 people had managed this business longer than this period. (3) There were 46 jamu makers who had basic educational background while five people did not finish their school. Observation also identified 29 sellers who had graduated from junior high school and six sellers hold the highest educational stratum. (4) The majority of respondents earned approximately 3 million rupiahs per month (32 sellers), while 15 sellers earned for over three million rupiahs per month. (5) Many jamu makers domiciled in West Jakarta which were spread across Greater Jakarta, e.g., North Jakarta, East Jakarta, Central Jakarta, Bogor, Tangerang, and Bekasi.

The profile of respondents in the second group, namely: (1) the same as before, the highest numbers were in the forties to fifties consisting of 29 people. There were only 3 people in their sixties, while 8 people were the youngest. (2) The period of running the herbal-medicine business for ten years was done by 46 people. Even eight jamu peddlers had been running their business for 31 years. (3) Similar to another group, 47 sellers graduated from junior high school, while 11 peddlers got higher education. Meanwhile, 25 people graduated from elementary school and 3 women were classified as acquired informal education. (4) There were thirty jamu peddlers' who earned the income approximately 3 million rupiahs per month. In fact, as many as 16 sellers earned over three million rupiahs per month (5). Most of the respondents were living in South Jakarta and other bufferzones of Jakarta.

Unfortunately, $59.30 \%$ of the members in first group came from a low level of formal education, while in the second group they were only $32.56 \%$. In line with the variation, the differences in response would be examined. Basically, the women came from several counties in Central Java, especially some regions at Sukoharjo, Wonogiri, and Karanganyar. Moreover, recently many women and girls from other regions have also participated in taking the opportunity in this sector. They have been wandered for a long time in Greater Jakarta or other cities e.g., Surabaya, Bandung, Semarang. In the early stage of running smallscale business, the sellers used to follow their mothers, sisters, grandmothers, or aunts to learn about how to make a variety of jamu and to get the territory for selling purpose.
This illustrates the spirit of women to help their husbands in fulfilling their household economy.

\subsection{The Results of Statistical Tests}

The scores of Cronbach's Alpha are proven higher than 0.70 in two constructs. The biggest score is 0.869 in QMM, whereas the smallest score is 0.728 in QMS. Other results are found in the value of 0.844 in QMI, 0.759 in QMO, 0.822 in QMR, and 0.762 in performance. Those scores are higher than 0.70 , so the data are reliable for further analyses purpose. Furthermore, the results of validity test are elaborated on Table 1 and Table 2, which show the entire items are higher than 0.20 . The results indicate entire indicators are valid.

Other testing results in the various grades of the score of KMO. The study finds a high score, especially QMI (0.830), QMM (0.855), and QMR (0.800). The results are indicated as meritorious or useful to the analysis. The score in QMO is 0.782 which is purposed as middling or more enough to be used to the next analysis. When compared with the previous results, specifically QMS and performance resulted in a value lower than 0.60 or in the mediocre category so that it was considered sufficient for further analysis. Entirely, the results of the testing of Bartlett do not reach 5\% that signing the proper of factor analysis.

Table 1 The scores of validity of QM indicators

\begin{tabular}{ccc|ccc}
\hline No & Indicators & Validity & No & Indicators & Validity \\
\hline 1 & QMI1 & 0.551 & 20 & QMM10 & 0.491 \\
\hline 2 & QMI2 & 0.554 & 21 & QMO1 & 0.541 \\
\hline 3 & QMI3 & 0.689 & 22 & QMO2 & 0.472 \\
\hline 4 & QMI4 & 0.672 & 23 & QMO3 & 0.680 \\
\hline 5 & QMI5 & 0.504 & 24 & QMO4 & 0.645 \\
\hline 6 & QMI6 & 0.557 & 25 & QMO5 & 0.445 \\
\hline 7 & QMI7 & 0.585 & 26 & QMS1 & 0.454 \\
\hline 8 & QMI8 & 0.512 & 27 & QMS2 & 0.573 \\
\hline 9 & QMI9 & 0.516 & 28 & QMS3 & 0.352 \\
\hline 10 & QMI10 & 0.470 & 29 & QMS4 & 0.433 \\
\hline 11 & QMM1 & 0.643 & 30 & QMS5 & 0.386 \\
\hline 12 & QMM2 & 0.666 & 31 & QMS6 & 0.677 \\
\hline 13 & QMM3 & 0.702 & 32 & QMR1 & 0.475 \\
\hline 14 & QMM4 & 0.733 & 33 & QMR2 & 0.428 \\
\hline 15 & QMM5 & 0.584 & 34 & QMR3 & 0.593 \\
\hline 16 & QMM6 & 0.564 & 35 & QMR4 & 0.681 \\
\hline 17 & QMM7 & 0.612 & 36 & QMR5 & 0.533 \\
\hline 18 & QMM8 & 0.525 & 37 & QMR6 & 0.661 \\
\hline 19 & QMM9 & 0.533 & 38 & QMR7 & 0.626 \\
\hline
\end{tabular}

Table 2 The scores of validity of performance indicators

\begin{tabular}{l|c|c}
\hline Indicators & Code & Validity \\
\hline Giving the profit & CP-1 & 0.563 \\
\hline Stability of sales & CP-2 & 0.481 \\
\hline Respect to quality & CP-3 & 0.610 \\
\hline Focus to supplier quality & CP-4 & 0.403 \\
\hline Good image & BP-1 & 0.453 \\
\hline Customer satisfaction & BP-2 & 0.501 \\
\hline Good relationship & BP-3 & 0.406 \\
\hline
\end{tabular}




\subsection{The Results of Hypothesis Testing}

The results of this study explore the differences in level along with the ingredient preparation in the early stage until the customers' consumption. This is mentioned as the production aspect (see Table 3 ). The other stages capture the supporting activities in serving the customers and making good relationships within and outside of the community of jamu peddler (see Table 4). This research seems to have a significant difference, especially in four dimensions (e.g., QMI, QMM, QMO, and QMR). The result also proves that the scores of significant are less than $5 \%$. Therefore, the four hypotheses $\left(\mathrm{H}_{1 \mathrm{a}}, \mathrm{H}_{1 \mathrm{~b}}, \mathrm{H}_{1 \mathrm{c}}\right.$, and $\left.\mathrm{H}_{1 \mathrm{e}}\right)$ could not be rejected, while the $\mathrm{H}_{1 \mathrm{~d}}$ could not be accepted.

Table 3 Hypotheses testing in production aspect

\begin{tabular}{lcccc}
\hline Information & QMI & QMM & & QMO \\
\hline Mann-Whitney U & 2789.00 & 2530.00 & 2831.50 \\
\hline Wilcoxon W & 6530.00 & 6271.00 & 6572.50 \\
\hline$Z$ & -2.79 & -3.59 & -2.68 \\
\hline $\begin{array}{l}\text { Asymp. Sig. } \\
\text { (2-tailed) }\end{array}$ & .005 & .000 & .007 \\
\hline Hypothesis & H1a & H1b & H1c \\
\hline Status & Accepted* & Accepted* & Accepted* \\
\hline Sign * significant 1-5\% & & \\
\hline
\end{tabular}

Table 4 Hypotheses testing in management aspect

\begin{tabular}{lcc}
\hline Information & QMS & QMR \\
\hline Mann-Whitney U & 3279.00 & 2772.50 \\
\hline Wilcoxon W & 7020.00 & 6513.50 \\
\hline Z & -1.29 & -2.85 \\
\hline Asymp. Sig. (2-tailed) & .197 & .004 \\
\hline Hypothesis & H1d & H1e \\
\hline Status & Rejected & Accepted* \\
\hline Sign * significant 1-5\% & & \\
\hline
\end{tabular}

Table 5 The Scores of Mean Rank and Sum of Ranks

\begin{tabular}{ccccc}
\hline \multirow{2}{*}{ No } & \multirow{2}{*}{ Code } & \multirow{2}{*}{ Group } & \multicolumn{2}{c}{ Ranking } \\
\cline { 4 - 5 } & & & Mean & Sum \\
\hline 1 & QMI & 1 & 75.93 & 6530.00 \\
\hline 2 & QMI & 2 & 97.07 & 8348.00 \\
\hline 3 & QMM & 1 & 72.92 & 6271.00 \\
\hline 4 & QMM & 2 & 100.08 & 8607.00 \\
\hline 5 & QMO & 1 & 76.42 & 6572.50 \\
\hline 6 & QMO & 2 & 96.58 & 8305.50 \\
\hline 7 & QMS & 1 & 81.63 & 7020.00 \\
\hline 8 & QMS & 2 & 91.37 & 7858.00 \\
\hline 9 & QMR & 1 & 75.74 & 6513.50 \\
\hline 10 & QMR & 2 & 97.26 & 8364.50 \\
\hline 11 & CP & 1 & 77.10 & 6630.50 \\
\hline 12 & CP & 2 & 95.90 & 8247.50 \\
\hline 13 & BP & 1 & 90.02 & 7742.00 \\
\hline 14 & BP & 2 & 82.98 & 7136.00 \\
\hline
\end{tabular}

Next, data analysis results are the mean rank or sum of ranks in the stages of quality management and performance. For instance, Table 5 illustrates the mean rank of QMI on Group 1 (75.93), which is less than QMI on Group-2 (97.07), whereas automatically the same patterns have occurred in the sum of ranks. The scores show the real disparity between the two groups so that the comparison could explain the reason for accepting the hypothesis of $\mathbf{H}_{1 \mathbf{a}}$. Similar patterns also occur in QMM, QMO, QMR, and CP between the two groups of jamu peddlers. Therefore, the results are able to support some hypotheses, e.g., $\mathbf{H}_{1 \mathbf{b}}, \mathbf{H}_{1 \mathbf{c}}, \mathbf{H}_{1 \mathbf{e}}$, and $\mathbf{H}_{2 \mathbf{a}}$. Related to the rejection of hypothesis on the service quality process $\left(\mathbf{H}_{1 \mathbf{d}}\right)$, it could be explained on the same table. The score of the mean rank of QMS in Group 1 (81.63) is less than the scoring in Group 2 (91.37). The result of the comparison shows less disparity between the two groups, so it could explain the reason for rejecting the hypothesis.

Table 6 Hypotheses testing in performance aspect

\begin{tabular}{lcc}
\hline Information & $\mathrm{CP}$ & $\mathrm{BP}$ \\
\hline Mann-Whitney U & 2889.50 & 3395.00 \\
\hline Wilcoxon W & 6630.50 & 7136.00 \\
\hline Z & -2.58 & -.97 \\
\hline Asymp. Sig. (2-tailed) & .010 & .331 \\
\hline Hypothesis & H2a & H2b \\
\hline Status & Accepted & Rejected \\
\hline Sign * significant 5\% & & \\
\hline
\end{tabular}

In Table 6, this research reveals the significant differences of perception about performance between Group-1 and Group-2, especially about the competitive power. This result provides the score of 0.010 so that $\mathbf{H}_{2 \mathbf{a}}$ could be accepted. On contrary, the point of BP is insignificant which indicating that $\mathbf{H}_{2 \mathbf{b}}$ could not be accepted. The acceptance of hypothesis about competitive power $\left(\mathbf{H}_{\mathbf{2}} \mathbf{)}\right.$ is caused by less contradiction between the mean of rank on Group 1 (77.10) and that in Group 2 (95.90). It shows the real disparity between the two groups, so the comparison properly supports the acceptance of hypothesis $\mathbf{H}_{2}$ a. Furthermore, the rejection of $\mathbf{H}_{2 b}$ is caused by less contradiction in the mean rank of bargaining power in Group 1 (90.02) and Group 2 (82.98). In this case, the exception has occurred which illustrates the decreasing perception among sellers in understanding the items of bargaining power, especially regarding good image and good relationship. Based on these results, the mechanism of quality cycle could be implemented for improving the knowledge associated with both constructs. Related to the sustainable development issues, the output can be as a tool in sustaining the herbs community in Greater Jakarta or other cities. Eventually, this approach can be used to overcome the volatility of perception in understanding the dimensions of bargaining power.

\subsection{Discussions}

This study found a difference in the perception of input preparation. It proves that in Group-2 occurred the increasing perception in the input preparation stages. However, the jати makers should be encouraged to practice the procedure of giving attention to expiry dates, especially on the materials manufactured by small-medium enterprises, large enterprises, and the traditional medicine industry. It shows 
the differences in perception of the making of jamu. In Group-2, it occurred the increasing perception of the making stages. Nevertheless, the makers have to be motivated to pack the liquid jamu in the glass bottles. Practically, many sellers use plastic bottles which are unrecommended as a packaging for liquid drink.

Furthermore, the result revealed the difference in perception of output processing, which is shown by the increasing perception in Group-2. Thus, they must be educated about avoiding the leftover and taking care of the dosage. The result identified the differences in perception of building the social relationship, which is shown by the increase of perception in Group-2. The jamu makers have to be fostered to make a relationship with society and maintain environmental hygiene e.g., managing the waste, keeping the cleanliness of water source, and avoiding contact with the domesticated animals such as cats, dogs, chicken, birds, rats, etc.

Lastly, this study also revealed the differences in perception of competitive power, which is shown by the increasing perception in Group-2. Nevertheless, they have to be motivated to respect the stability of sales and suppliers' quality. The changing of lifestyles could decrease the demand and disturb the stability of sales. The sustainability of the community requires to be fostered by innovation.

On contrary, this study did not find the differences in the two aspects. The first reason is that jamu peddlers maintain a limited number of buyers, but they are able to keep customer's reliance since the early consumption of jamu products. In normal condition, everyday they serve loyal customers at different places in the morning and afternoon. The abilities form the same perception of quality services among peddlers. The second, while running the business, these women show a friendly character and give attention to their loyal customers. They are able to meet some criteria of good relationships, customer satisfaction, and good image. This sector is related to the availability of herbal medicine to society so that in the pandemic, the existence of herbal medicine traders is very helpful to the community. Along with the Covid-19 pandemic, the awareness of personal hygiene and the cleanliness of the process of making until serving the herbal products, must be a priority. The use of masks and the implementation of health protocols must be carried out by the herbal sellers. This behaviour supports their role in providing daily herbal drink to the society.

Based on [28], the implementation of quality management through quality cycle has some benefits. This moment can foster self-improvement and develop mutual benefit among jamu peddlers. In line with [29], it also contributes to build a quality culture. According to [4], јати is a system that is related to small-scale enterprises, traditional knowledge, and social empowerment. Therefore, it has the effects toward the achievement of some goals in sustainable development. [5] noted "that quality is an ever-changing state", which means that "the quality today may not be good enough to be considered to the quality tomorrow". They must understand the change. Constraint relates to educational level and the scale of their business in the bottom pyramid. The peddler's community needs an accompanying program through the quality cycle approach. In line with [9], an education system is needed related to production improvements and management aspects, creativity, and innovation. It will help sustain the herbal enterprises.

The results of this study focus on herbal makers or sellers who work in traditional ways. However, it does not rule out that these commercial activities can be developed in a more professional manner. The jamu products is related to the healing tradition of ancestors. In ensuring the sustainability, this study improves early design for preparing the system of managing quality for the herbal enterprises.

Herbal has the potential to be developed professionally. Innovations such as herbal cafes, fitness facilities, or beauty salons are back to promoting herbal products. In addition, during the pandemic, it encourages consumer behavior to buy herbal products to maintain the stamina. To support the business in a professional manner, an information system is needed as shown in Figure 1. There are three databases for information, namely (1) Diseases database that can usually be cured by consuming herbs, (2) Herbal plants / raw material database that is used in the combination of herbal products. It is useful to ensure adequate supply, and (3) The herbal medicine manual contains recipes and methods of preparation until delivery processing. The last is to preserve the consistency of the taste and the benefit of the herbal products. Regarding the ingredients [2], Indonesian nature is known as a mega center for biodiversity that can be processed as raw material for traditional medicine so that this potential should support the sustainability of the raw material supplies to the herbal enterprises.

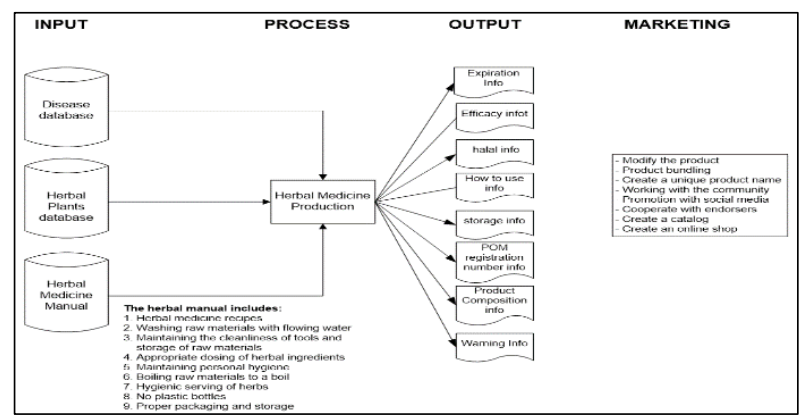

Figure 1 Data flowchart diagram in jamu-business sector

The output produced is not only the products, but also the valuable information to consumers e.g., expiration period, benefits, halal certificates, BPOM registration, composition information, as well as the usage and storage methods. The marketing approach is directed to product modification, product bundling in collaboration with the herbal community, the use of social media and online systems. The diagram is an initial description so that professionally it can be developed through an application. This will help develop the business such as a herbal café without ignoring the jamu peddlers community.

\section{CONCLUSIONS}

This research found the significant differences in four stages of quality management and competitiveness among herbal 
peddlers. It traced equal perception of "service quality and bargaining power". This illustrates the benefit of TQC in fostering the quality culture toward community. Basically, the value of quality is inherent in customers who use the products or services. Hence, the effort for improving the quality meets the lifestyle of customers for sustaining their demand. The final goal is to create awareness to gain the profits without ignoring the customers' risks. This is essential in the pandemic period so that loyal consumers can always receive the benefits of consuming herbal products. This result is able to deliver contributions to the government in making the policy to communities. The next study might emphasize the spirit of entrepreneurs as a model of cultural entrepreneurship.

\section{ACKNOWLEDGMENTS}

Authors would like to thank the Ministry of Research, Technology, and Higher Education of the Republic of Indonesia for funding this research with grant No. 527-SPKDIR.PPKM/UNTAR/VII/2017. We also thank Universitas Tarumanagara for supporting and facilitating this research.

\section{REFERENCES}

[1] Depkes, "Peraturan Menteri Kesehatan Republik Indonesia nomor 006 tahun 2012 tentang industri dan usaha obat tradisional', Peraturan Menteri Kesehatan RI. [Regulation of the Minister of Health of the Republic of Indonesia No. 006 Year 2012 on Tradition Medicine Industry and Business," vol. 7, no. 6, pp. 1-25, 2012.

[2] K. Nuringsih and Rodhiah, "Fostering Jamu Peddler's Quality System: Linking Women Empowerment and Cultural Preservation," in Proceedings of the Sixth International Conference on Entrepreneurship and Business Management, Hanoi, Vietnam November 16-17 2017.

[3] M. C. Torri, "Knowledge and Risk Perceptions of Traditional Jamu Medicine among Urban Consumers," European Journal of Medicinal Plants, vol. 3, no. 1, pp. 25-39, 2013.

[4] M. C. Torri, "The jamu system: Linking small-scale enterprises, traditional knowledge and social empowerment Among Woman in Indonesia," Journal of International Women's Studies, vol. 15, no. 4, pp. 488$501,2012$.

[5] D. L. Goetsch and S. B. Davis, Introduction to Total Quality. Second Ed. New Jersy: Prentice-Hall Inc., 1997.

[6] D. Gharakhani, H. Rahmati, M. R. Farrokhi, and A. Farahmandian, "Total Quality Management and Organizational Performance," American Journal of
Industrial Engineering., vol. 1, no. 3, pp. 46-50, 2013.

[7] E. Sadikoglu and H. Olcay, "The Effects of Total Quality Management Practices on Performance the Reasons of and the Barriers to TQM Practices in Turkey," Advances in Decision Science, Hidawi Publising Corporation, vol. 14, pp. 1-17, 2014.

[8] A. M. Mosadeghrad, "Obstacles to TQM success in health care systems," International Journal of Health Care Quality Assurance, vol. 26, no. 2, pp. 147-173, 2013.

[9] H. J. Harrington, F. Voehl, and H. Wiggin, "Applying TQM to the construction industry," The TQM Journal, vol. 24, no. 4, pp. 352-362, 2012.

[10] H. Alghamdi, "Toward Better Understanding of Total Quality Management (TQM)," Journal of Business \& Economic Policy, vol. 3, no. 4, pp. 29-37, 2016.

[11] N. Bouranta, E. Psomas, M. F. Suárez-Barraza, and C. Jaca, "The key factors of total quality management in the service sector: a cross-cultural study," Benchmarking, 2019.

[12] M. R. Chaudhary and Mr. Lalit Yadav, "Impact of Quality Circle Towards Employees \& Organization A Case Study," IOSR Journal of Engineering, vol. 02, no. 10, pp. 23-29, 2012.

[13] S. SYLA, "Quality Circles: what do they mean and how to implement them?," International Journal of Academic Research in Business and Social Sciences, vol. 3, no. 12, pp. 243-251, 2013.

[14] N. Shireen, "Quality Circle: A Fundamental Unit of Increase Profitability," International Journal of Management and Commerce Innovations, vol. 2, no. 1, pp. 30-34, 2014.

[15] S. Subramanya and D. Muralidhar.S, "A Study on Impact of Quality Circles in Promoting Employee Performance at Service Sector," International Journal of Business and Administration Research Review, vol. 1, no. 1, pp. 272-273, 2016.

[16] A. Kalirawna, R. Attri, and N. Dev, "Identification of Factors in I.mplementation of Quality Circle," International Journal of Advance Research in Science and Engineering, no. 4, special issue (01) pp. 614-618, 2015. 
[17] K. Nuringsih and Rodhiah, “Applying Total Quality Model for Improving Quality in the Grassroot Jamu Enterprise," in Proceedings of the $2^{\text {nd }}$ International Conference on Advance and Scientific Innovation, pp. 111, Banda Aceh, Indonesia June $18^{\text {th }} 2019$.

[18] V. V Gaikwad and A. V Gaikwad, "Quality Circle as an Effective Management Tool : A Case Study of Indira College of Engineering and Management Library," ICAL-Poster Papers, pp. 650-653, 2009.

[19] K. Ooi, "TQM and Knowledge Management: Literature Review and Proposed Framework," African Journal of Business Management, vol. 3, no. 11, pp. 633-643, 2009.

[20] S. A. Brah and W. K. Chong, "Relationship between Total Productive Maintenance and Performance," International Journal of Production Research, June, pp. 1-19, 2004.

[21] I. S. Salaheldin, "Critical Success Factors for TQM Implementation and Their Impact on Performance of SMEs," International Journal of Production and Performance Management, vol. 58, no. 3, pp. 215-237, 2008.

[22] E. N. Kibe and D. K. Wanjau, "The Effect of Quality Management Systems on the Performance of Food Processing Firms in Kenya," IOSR Journal of Business Management, vol. 16, no. 5, pp. 61-72, 2014.

[23] J. J. Tarí and V. Sabater, "Quality Tools and Techniques: Are They Necessary for Quality Management?," International Journal Production Economic, vol. 92, pp. 267-280, 2003.

[24] Y. M. D. Almansour, "The Impact of Total Quality Management Components on Small and Medium Enterprises' Financial Performance in Jordan," Journal of Arts, Science \& Commerce, vol. III, no. January, pp. 87-91, 2012.

[25] K. A. M. Ali and H. H. A. Talib, "Total Quality Management Approach for Malaysian Food Industry: Conceptual Framework," Journal of Advance Management Science, vol. 1, no. 4, pp. 405-409, 2013.

[26] H. H. A. Talib, K. A. M. Ali, and F. Idris, "Quality Management Framework for the SME's food Processing Industry in Malaysia," International Food Research Journal, vol. 20, no. 1, pp. 147-164, 2013.
[27] G. Garson and David, Partial Least Square: Regression \& Structural Equation Models. Blue Book Series, Statistical Publishing Associates, 274 Glenn Drive, Asheboro, NC 27205 USA., 2016.

[28] P. Cornelison, "The Effectiveness of Total Quality Management Principles in the Printing Industry," California, 2013. 